\title{
The correlation of symptoms severity and objective measures in patients with lower urinary tract symptoms
}

\author{
Basri Cakiroglu ${ }^{1, ~ *}$, Ramazan Gozukucuk ${ }^{2}$, Orhun Sinanoglu ${ }^{3}$, Suleyman Hilmi Aksoy ${ }^{4}$, \\ Tuncay Tas ${ }^{5}$, Seyit Erkan Eyyupoglu ${ }^{6}$, Bekir Sami Uyanik \\ ${ }^{1}$ Hisar Intercontinental Hospital, Department of Urology, 34768 Umraniye, Istanbul, Turkey \\ ${ }^{2}$ Hisar Intercontinental Hospital, Department of Infectious and Clinical Microbiology, 34768 Umraniye, Istanbul, Turkey \\ ${ }^{3}$ Maltepe University, Medical School Department of Urology, 34857 Maltepe, Istanbu,Turkey \\ ${ }^{4}$ Hisar Intercontinental Hospital, Department of Radiology, 34768 Umraniye, Istanbul,Turkey \\ ${ }^{5}$ Taksim Training and Research Hospital, Department of Urology, 34433 Taksim, Istanbul, Turkey \\ ${ }^{6}$ Sabuncuoglu Serefettin Training and Research Hospital, Department of Urology, 05200 Amasya, Turkey \\ ${ }^{7}$ Hisar Intercontinental Hospital, Department of Clinical Biochemistry, 34768 Umraniye, Istanbul, Turkey
}

\section{Email address:}

drbasri@gmail.com (B. Cakiroglu),rgozukucuk@hisarhospital.com (R. Gozukucuk), orhundr@hotmail.com (O. Sinanoglu), saksoy@hisarhospital.com (S. H. Aksoy), Tastuncay@gmail.com (T. Tas), seeseesee@hotmail.com (S. E. Eyyupoglu), bsuyanik@hisarhospital.com (B. S. Uyanik)

\section{To cite this article:}

Basri Cakiroglu, Ramazan Gozukucuk, Orhun Sinanoglu, Suleyman Hilmi Aksoy, Tuncay Tas, Seyit Erkan Eyyupoglu, Bekir Sami Uyanik. The Correlation of Symptoms Severity and Objective Measures in Patients with Lower Urinary Tract Symptoms. Clinical Medicine Research. Vol. 2, No. 6, 2013, pp. 135-139. doi: 10.11648/j.cmr.20130206.14

\begin{abstract}
Purpose: To evaluate the correlation between international prostate symptom score (IPSS) and objective measures of lower urinary tract symptoms to estimate the grade of infravesical obstruction in benign prostatic hyperplasia (BPH). Methods: The data of 152 male patients examined in urology outpatient clinic with lower urinary tract symptoms (LUTS) were retrospectively rewieved between January 2010 and December 2011. Prostate volume, detrusor wall thickness (DWT) and post voiding residue (PVR) were evaluated with suprapubic ultrasound. The patients were distributed in three groups according to IPSS values; 1st, lower IPSS group ( $\mathrm{n}=39)$, 2nd, moderate IPSS group $(\mathrm{n}=80)$ and 3rd, higher IPSS group ( $\mathrm{n}=33$ ). IPSS, BWT, prostate volume, postvoiding residue (PVR), and maximum urine flow (Qmax) values were compared. Results: The mean age was $52.9 \pm 9.0$ years. There were significant differences between the three groups for total PSA, in terms of prostate volume, DWT, PVR, Qmax, Qave values. There was a significant correlation between IPSS questionnaire results and PVR, Qmax and Qave $(P<0.05)$. PVR, Qmax and PVR values revealed especially strong positive correlations with symptoms severity or IPSS (Pearson /Spearman's correlation coefficients were $0.441 ; \mathrm{p}<0.000$ and $0.446 ; \mathrm{p}<0.000$ respectively; Table 3). Conclusions: There are significant correlations between symptoms severity (IPSS) and objective BPH-related parameters, such as age, PSA, prostate volume, DWT, PVR, Qmax, Qave and QoL. The measurements of especially DWT, PVR and Qmax are promising noninvasive tools to predict the grade of LUTS in men and is reflected in IPSS severity.
\end{abstract}

Keywords: Uroflowmetry, Prostate Volume, PSA, IPSS, DWT, BPH, LUTS

\section{Introduction}

Although obstructive disorders of the lower urinary tract may also be caused by other diseases, such as bladder neck contractures, urethral valves, or external sphincter dyssynergia, lower urinary tract symptoms (LUTS) is mostly due to benign prostate hyperplasia(BPH) in the elderly men [1]. LUTS comprise frequency, urgency, weak stream, straining and nocturia. In order to evaluate the severity of the symptoms, several scoring systems have been created, among which the International Prostate Symptom Score (IPSS) is gained wide acceptance [2]. However, since IPSS is a subjective indicator of LUTS, the objective parameters which include prostate volume, uroflowmetry, prostate-specific antigen (PSA) and residual urine volume, are also used to assess the severity of the illness and effect of treatment. In order to evaluate LUTS severity, ultrasonography being a noninvasive, rapid, 
inexpensive technique with high diagnostic accuracy has been widely used in urological practice. Ultrasound-derived noninvasive tests for the evaluation of LUTS severity can provide measurements of detrusor wall thickness DWT, postvoiding residual urine volume (PVR), and prostate and bladder volumes $[3,4]$. Furthermore, the correlation between the severity of subjective symptoms and objective parameters remains unclear. Hence, our purpose in this study was to analyze the correlation of ultrasound-derived noninvasive tools (DWT when the bladder is full, PVR, and prostate volumes), uroflowmetry parameters as well as quality of life in patients' groups having mild, moderate and severe symptoms. Our hypothesis was that IPSS would differentiate severe cases requiring immediate intervention and predict the degree of the severe infravesical obstruction in $\mathrm{BPH}$ patients.

\section{Methods}

The data of 152 male patients examined in urology outpatient clinic with lower urinary tract symptoms (LUTS) were retrospectively rewieved between January 2010 and December 2011.

Patients with any of several other diseases which are potential risk factors affecting urinary symptoms, including severe heart disease, renal disease, neurological disease, urinary tract infection or previous transurethral surgery, were excluded from the study. All patients included in the study were subjected to a standardized program, including history-taking with reference to IPSS, physical examination (including digital rectal examination), biochemistry

(including PSA), suprapubic ultrasound (including prostate volume, DWT and PVR), and uroflowmetry (including Qmax and average flow rate (Qave)). The patients were distributed in three groups according to IPSS values1st, lower IPSS group (0-7); $(n=39), 2 n d$, moderate

IPSS group (8-19); $(\mathrm{n}=80)$ and 3rd, .higher IPSS group(20-35); $(n=33)$. DWT was measured at the anterior bladder wall with the use of a 7.5-MHz linear ultrasound array. When the bladder was full, two ultrasonographic measurements of the anterior bladder wall in longitudinal scan and transverse scan were recorded, and the average of the two measurements was taken as the final DWT value in millimeters. Total PSA, prostate volume, DWT, PVR, Qmax, Qave and QoL values were compared according to IPSS groups. The correlation between objective parameters and IPSS groups as well as the correlation among objective parameters were also evaluated.

\subsection{Statistical Analysis}

For statistical analyses, a commercially available software package (Statistical Package for Social Sciences, version 16.0, SPSS Inc., Chicago, Illinois, USA) was used. Descriptive statistics and the Spearman correlation coefficient (r) were used to describe the association between IPSS score and the various parameters tested. Independent sample $\mathrm{T}$ and Mann- Whitney $\mathrm{U}$ tests were also used in this study. A p value less than 0.05 was thought to have significance.

\section{Results}

$(1 ; 0-7,2 ; 8-19,3 ; 20-35)$

\begin{tabular}{llll}
\hline & $\mathbf{1}(\mathbf{N}=\mathbf{3 6})$ & $\mathbf{1}(\mathbf{N}=\mathbf{8 0})$ & $\mathbf{1}(\mathbf{N}=\mathbf{3 0})$ \\
\hline Age & $52.9 \pm 9.0$ & $52.9 \pm 9.0$ & $52.9 \pm 9.0$ \\
Prostate Volume $(\mathrm{mL})$ & $34.0 \pm 16.0$ & $38.8 \pm 15.7$ & $66.6 \pm 47.7$ \\
total PSA $(\mathrm{ng} / \mathrm{mL})$ & $0.98 \pm 0.75$ & $1.48 \pm 1.34$ & $3.40 \pm 3.35$ \\
DWT $(\mathrm{mm})$ & $3.33 \pm 0.63$ & $3.89 \pm 0.94$ & $4.38 \pm 0.93$ \\
PVR $(\mathrm{mL})$ & $31.5 \pm 26.5$ & $55.7 \pm 39.5$ & $107.2 \pm 91.0$ \\
Qmax $(\mathrm{mL} / \mathrm{s})$ & $23.3 \pm 9.8$ & $16.6 \pm 6.9$ & $12.0 \pm 4.6$ \\
Qave $(\mathrm{mL} / \mathrm{s})$ & $12.9 \pm 5.5$ & $9.1 \pm 3.8$ & $6.2 \pm 2.6$ \\
QoL & $1.29 \pm 1.27$ & $2.90 \pm 1.16$ & $4.70 \pm 0.79$ \\
\hline
\end{tabular}

DWT; Detrusor wall thickness, PVR; Post voiding residue, Qmax; maximum flow,

Qave; Average flow, QoL; Quality of life.

Values are mean $\pm \mathrm{SD}$

Table 2. The comparison of objective parameters according to IPSS scores

\begin{tabular}{|c|c|c|c|c|c|c|c|}
\hline & & $\begin{array}{l}\text { Prostate } \\
\text { Volume }\end{array}$ & tPSA & DWT & PVR & Qmax & Qave \\
\hline Group1 vs & $\mathrm{t} / \mathrm{z}$ & 1.703 & 2.273 & 3.315 & 3.529 & 4.207 & 4.259 \\
\hline Group 2 & (p) & $(0.089)$ & $(0.023)^{*}$ & $(0.001)^{* *}$ & $(0.000)$ & $(0.000)$ & $(0.000)$ \\
\hline Group1 vs & $t / z$ & 3.966 & 4.318 & 5.391 & 5.094 & 5.754 & 6.059 \\
\hline Group 3 & (p) & $(0.000)$ & $(0.000)$ & $(0.000)$ & $(0.000)$ & $(0.000)$ & $(0.000)$ \\
\hline Group2 vs & $t / z$ & 3.626 & 3.521 & 2.386 & 3.695 & 3.407 & 3.862 \\
\hline Group 3 & (p) & $(0.000)$ & $(0.000)$ & $(0.019)^{*}$ & $(0.000)$ & $(0.001)^{* *}$ & $(0.000)$ \\
\hline
\end{tabular}

${ }^{*} \mathrm{p}<0.05, * * \mathrm{p}<0.01$, others $\mathrm{p}<0.001$

$\mathrm{t} / \mathrm{z}$ : Coefficients of statistical tests (independent Sample T test, Mann-Whitney U test)

DWT; Detrusor wall thickness, PVR; Post voiding residue, Qmax; maximum flow,

Qave; Average flow, QoL; Quality of life. 
The patients were divided into three groups according to the severity of the symptoms considering IPSS. The mean age was $52.9 \pm 9.0$ years (Table 1). There were significant differences between the three groups for total PSA, in terms of prostate volume, DWT, PVR, Qmax, Qave values. In Table 2, the comparison of differences in objective data values among IPSS groups were listed with correlation coefficients. Prostate volumes, total PSA, DWT, PVR, in 3rd group were significantly higher compared to 1 st and 2nd groups whereas Qmax and Qave were significantly lower compared to 1 st and 2 nd groups $(\mathrm{p}<0.05)$ (Figure 1$)$. Total PSA, DWT, PVR, in 2nd group were significantly higher compared to 1st group whereas Qmax and Qave

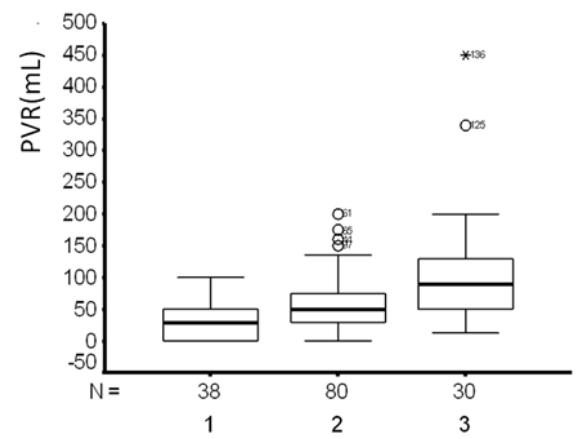

were significantly lower compared to 1 st $\operatorname{group}(\mathrm{p}<0.05)$. There was a significant correlation between IPSS questionnaire results and PVR, Qmax and Qave $(\mathrm{p}<0.05)$. Qmax and PVR values revealed especially strong positive correlations with symptoms severity or IPSS (Pearson /Spearman's correlation coefficients were $0.441 ; \mathrm{p}<0.000$ and $0.446 ; \mathrm{p}<0.000$ respectively; Table 3 )(Figure 1). Other strong correlations were also present between the age and prostate volume $(\mathrm{r}=0.464 ; \mathrm{p}<0.000)$.age and total $\operatorname{PSA}(\mathrm{r}=0.466 ; \mathrm{p}<0.000)$, prostate volume and $\mathrm{PVR}(\mathrm{r}=0.415 ; \mathrm{P}<0.000)$, prostate volume and Qmax $(\mathrm{r}=0.382 ; \mathrm{p}<0.000)$, DWT and $\operatorname{PVR}(\mathrm{r}=0.395 ; \mathrm{p}<$ 0.001 )(Figure 2).

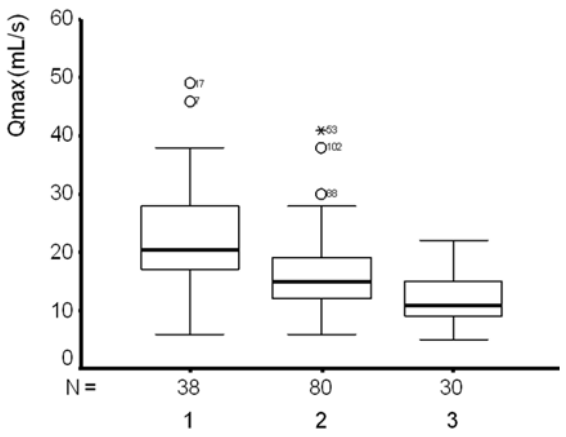

Figure 1. The correlation between the objective parameters and IPSS severity in LUTS (box plots) PVR: Post voiding residue, Qmax; maksimum flow.
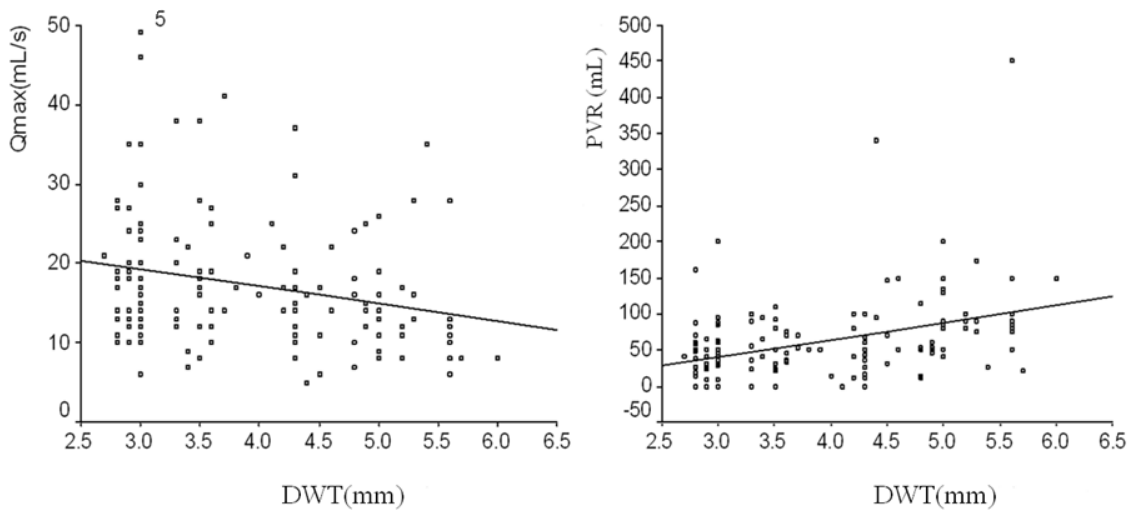

Figure 2. The correlation between the Qmax and PVR between BWT in LUTS (scatter plots) Qmax; maksimum flow. PVR: Post voiding residue

Table 3. The correlation between the objective parameters and IPSS

\begin{tabular}{ccc}
\hline & \multicolumn{2}{c}{$\begin{array}{c}\text { Pearson/Sperrman } \\
\text { Correlation }\end{array}$} \\
\hline & $\mathrm{r}$ & $\mathrm{p}$ \\
Age-Prostate volume & $0.464 \mathrm{~s}$ & $0.000^{* *}$ \\
Age-total PSA & $0.466^{\mathrm{s}}$ & $0.000^{* *}$ \\
Prostate volume-PVR & $0.415^{\mathrm{s}}$ & $0.000^{* *}$ \\
Prostate volume-Qmax & $-0.382^{\mathrm{s}}$ & $0.000^{* *}$ \\
DWT-PVR & $0.395^{\mathrm{s}}$ & $0.000^{* *}$ \\
DWT-Qmax & -.0248 & $0.002^{*}$ \\
DWT-Qave & $-0.241 \mathrm{~s}$ & $0.003^{*}$ \\
IPSS-PVR & $0.4411^{\mathrm{s}}$ & $0.000^{* *}$ \\
IPSS-Qmax & -0.446 & $0.000^{* *}$ \\
\hline
\end{tabular}

${ }^{*} \mathrm{p}<0.01,{ }^{*} \mathrm{p}<0.001, \mathrm{~s}$ Spearman Correlation

DWT; Detrusor wall thickness, PVR; Post voiding residue, Qmax; maximum flow, Qave;Average flow, QoL; Quality of life.

\section{Discussion}

LUTS include urinary frequency, urgency, weak stream, and nocturia and is the most common problem in BPH patients [5]. Several studies have shown that there are correlations between urinary symptoms namely IPSS and prostate volume, peak flow rate or residual urine volume [6,7]. However, others have found that objective parameters cannot predict the severity of symptoms in BPH patients or prostate volume is not correlated with LUTS severity $[8,9]$. A latter study with 1295 patients suggests that the correlation between objective parameters of $\mathrm{BPH}$ and LUTS was significant although it was hard to predict the severity of symptoms by these parameters [10]. Among noninvasive diagnostic modalities, such as uroflowmetry, 
PVR or prostate volume, DWT was found to be the most accurate test to evaluate lower urinary tract symptoms in men [11]. In the present study, we evaluated retrospectively the relationship between LUTS and non-invasive objective parameters in a small number of sample [12]. We found a significant correlation between IPSS and PVR or Qmax. Other strong correlations were also present between the age and prostate volume, age and total PSA, prostate volume and PVR, prostate volume and Qmax, also between DWT and PVR. The results of this study are in contrast to some series. In a study of 803 consecutive patients with LUTS and/or BPH, only a weak correlation was found between IPSS and Qmax or PVR whereas no correlation was found between IPSS and prostate volume. In another study where no correlation was found between PVR and bladder outlet obstruction, the authors claimed that the correlation between IPSS and objective parameters could be identified however; it was hard to predict the severity of symptoms from these parameters, because they showed a great overlap in groups with different severity of IPSS. Even in patients with severe symptoms, some of them still have a small prostate or higher Qmax, therefore, one could not make the treatment decision on IPSS alone. After an article explaining that the thickening of the detrusor muscle resulted from increased workload, similar to the heart in which the muscular wall thickens due to a valve stenosis, many studies started to be published revealing the predictive value of DWT in men with bladder outlet obstruction (BOO) [13-17]. A significant correlation was found between DWT and pressure flow studies (PFS), authors concluded that DWT can predict BOO as well as PFS and concluded that it can replace PFS in the diagnosis of BOO. Our results are in line with these studies as the correlation between DWT other objective parameters such as Qmax, Qave, and PVR was significant.

There are limitations of our study; Beside being retrospective in nature, the sample size was small and, although all of the ultrasonographic measurements were made by the same radiologist who was blinded to the IPSS results and LUTS severity of the patients, ultrasonography itself is a subjective assessment and operator dependent modality.

In conclusion, from all the data of the presented study, we can conclude that there are significant correlations between symptoms severity namely IPSS and objective BPH-related parameters, such as age, PSA, prostate volume, DWT, PVR, Qmax, Qave and QoL. Furthermore the suprapubic transabdominal ultrasonographic assessment of the lower urinary tract allows clinicians to assess LUTS severity in men without any morbidity unlike the invasive methods. The technique is simple and reliable with additional low intra- and inter- observer variability. We believe that the ultrasound measurements of especially DWT and PVR, as well as assessment of Qmax are promising noninvasive tools to predict the grade of LUTS in men and is reflected in IPSS severity.

\section{References}

[1] Roehrborn CG, McConnell JD. Etiology,pathophysiology, epidemiology, and natural history of benign prostatic hyperplasia. In: Campbell's urology. 8th ed. Philadelphia: Saunders, 2002. p. 1309-1311

[2] AUA Practice Guidelines Committee. AUA guideline on management of benign prostatic hyperplasia (2003). Chapter 1: diagnosis and treatment recommendations. J Urol, 2003. 170: p. $530-547$.

[3] Belal M, Abrams P. Noninvasive methods of diagnosing bladder outlet obstruction in men. Part 1. Non-urodynamic approach. J Urol, 2006. 176: p. 22-28.

[4] Wang JY, et al., Relationship between lower urinary tract symptoms and objective measures of benign prostatic hyperplasia: a Chinese survey. Chin Med J (Engl), 2008. 20; 121(20): p. 2042-5.

[5] Wu SL, et al., Natural history of benign prostatic hyperplasia. Chin Med J, 2006. 119: p. 2085-2089.

[6] Barry MJ, et al., The American Urological Association symptom index for benign prostatic hyperplasia. The Measurement Committee of the American Urological Association. J Urol, 1992. 148: p. 1549-1557.

[7] Madersbacher S, et al., Is obstruction predictable by clinical evaluation in patients with lower urinary tract symptoms? Br J Urol, 1997. 80: p. 72-77.

[8] Kezzeldin LA, et al., Correlation between uroflowmetry, prostate volume, postvoid residue, and lower urinary tract symptoms as measured by the international prostate symptom score. Urology, 1996. 48: p. 393-397.

[9] Tubaroa A, Vecchia CA. The relation of lower urinary tract symptoms with life-style factors and objective measures of benign prostatic enlargement and obstruction: an Italian survey. Eur Urol, 2004. 45: p. 767-772.

[10] Wang JY, et al., Relationship between lower urinary tract symptoms and objective measures of benign prostatic hyperplasia: a Chinese survey Chin Med J, 2008. 121(20): p. 2042-2045

[11] Tokgoz O, et al., Diagn Interv Radiol, 2012. 18: p. 277-281.

[12] Li MK, et al., An Asian multinational prospective observational registry of patients with benign prostatic hyperplasia, with a focus on comorbidities, lower urinary tract symptoms and sexual function. BJU Int, 2008. 101: p. 197-202.

[13] Zhang P, Wu ZJ, Gao JZ. Influence of bladder outlet obstruction and detrusor contractility on residue urine in patients with benign prostatic hyperplasia. Chin Med J, 2003. 116: p. 1508-1510

[14] Tubaro A, Miano L. Managing the consequences of obstruction. Eur Urol Suppl, 2002. 1: p. 21-27.

[15] Oelke M, et al., Increase in detrusor wall thickness indicates bladder outlet obstruction (BOO) in men. World J Urol, 2002. 19: p. 443-452.

[16] Levent Işıkay, et al., Lower urinary tract symptoms, prostate volume, uroflowmetry, residual urine volume and 
bladder wall thickness in Turkish men: a comparative analysis. Int Urol Nephrol, 2007. 39: p. 1131-1135.

[17] Kessler TM, et al., Ultrasound assessment of detrusor thickness in men. Can it predict bladder outlet obstruction and replace pressure flow study? J Urol, 2006. 175: p. 2170 2173. 